\title{
EARLY DETECTION OF TRICHOGRAMMA CHILONIS SEXES USING THE EGG COLOR AND SIZE OF ITS FACTITIOUS HOST, CORCYRA CEPHALONICA
}

\author{
F.X. Susilo ${ }^{1}$, Desta S. Romli ${ }^{2}$, Sunaryo ${ }^{3}$, and M. Solikhin ${ }^{1}$
}

\begin{abstract}
Early Detection of Trichogramma chilonis sexes using the egg color and size of its factitious host Corcyra cephalonica. This study was aimed to detect the sexes of Trichogramma chilonis Ishii (Hymenoptera: Trichogrammatidae) prior to their emergence using the egg color and size of their factitious host, Corcyra cephalonica (Lepidoptera: Pyralidae). A gray scale of $1-7$ was used to rank the egg color while a micrometer was used to observe the egg size under a dissecting microscope. Ten of newly laid $C$. cephalonica eggs were glued in two rows $(0.5 \mathrm{~cm} \times 0.4 \mathrm{~cm}$ distance $)$ on a piece of oviposition paper. Five replications of such batches were exposed in a test tube to a gravid T. chilonis female for 24 hours under 100 watts of illumination. Following the withdrawal from the oviposition arena the eggs were each observed daily for their color and size and the sex of the emerged T. chilonis progeny was documented. Binomial Z-test at 0.05 level of significance was used to validate the predicted proportion of $T$. chilonis sexes from five batches of 50 parasitized $C$. cephalonica eggs. The results showed as predicted that more $T$. chilonis female progeny emerged from light-colored $C$. cephalonica eggs (scale $2-5$ ) following oviposition by parent parasitoid or from larger C. cephalonica eggs $(\geq 500 \mu \mathrm{m})$.
\end{abstract}

Key words: sex, Trichogramma, early detection, Corcyra egg

\section{INTRODUCTION}

Trichogramma chilonis Ishii (Hymenoptera: Trichogrammatidae) has been used as a biological control agent against various insect pests attacking crops worldwide, including corn borers, sugarcane borers, and cotton bollworm (Li, 1994). The egg parasitoid that has been used to control sugarcane borers in Lampung, Indonesia was introduced from Java and formerly known (or misidentified) as $T$. australicum Girault. The parasitoid has been massreared in the laboratory and periodically released at the sugarcane field at Terusan Nunyai area, Central Lampung (owned by PT Gunung Madu Plantations) since 1976 (Sunaryo, 1988; Putri, 2006). In the laboratory the mass-rearing of T. chilonis is facilitated using eggs of the rice moth, Corcyra cephalonica (Stainton) (Lepidoptera: Pyralidae) as the factitious host.

The parasitization $T$. chilonis in the field population of sugarcane stemborer varies from $10 \%$ to 40\% (Dewi, 2007). In some occasions the parasitoid performance could even be lower than $10 \%$. Variations in the field conditions during the parasitoid release including weather and population dynamics of the host pest might have contributed to the parasitoid performance. In addition, the performance might also depend on the biological condition of the parasitoid itself, including its sex ratio. The parasitoid sex ratio which favors females (female-biased) would potentially better perform than that which favors males because only the females that actually sting, oviposit, and thus parasitize the host pest. It is therefore important that the sex ratio of $T$. chilonis be first considered before their release as the indicator of their potential performance in the field. However, the parasitoid sex is normally manifested after their emergence from the host eggs. The research question is thus as follows: Cand (or how can) T. chilonis sex be detected prior to emergence from their host eggs?

During the mass-rearing of $T$. chilonis in the laboratory, it has been observed that C. cephalonica eggs change in color and vary in size (Sunaryo, 1988). The parasitized eggs turn darker than unparasitized ones. Furthermore, variation in the dark coloration is also occurred within the parasitized egg group. This lead to further questions as follows: (1) Could the color variation in the parasitized host eggs be indicative of the sex of $T$. chilonis progeny developed therein? (2) Would the size of the host eggs exert some kind of preference of parental $T$. chilonis to lay eggs therein which developed into progeny of certain sex? The objective of this study was to detect the sex of $T$. chilonis prior to their emergence using the color and size of parasitized C. cephalonica eggs.

\footnotetext{
${ }^{1}$ Lecturer at Department of Plant Protection, Faculty of Agriculture, University of Lampung, Jl. Prof. Sumantri Brojonegoro No. 1, Bandar Lampung, 35145

${ }^{2}$ Alumnus from Department of Plant Protection, Faculty of Agriculture, University of Lampung, Jl. Prof. Sumantri Brojonegoro No. 1, Bandar Lampung, 35145

${ }^{3}$ Researcher at Biocontrol Research \& Development Laboratory, PT Gunung Madu Plantations, Terusan Nunyai, Central Lampung
} 


\section{MATERIALS AND METHODS}

The study was conducted at Research \& Development Laboratory, PT Gunung Madu Plantations, Terusan Nunyai, Central Lampung during Mei-August 2006. Two sets of experiment were set, i.e. characterization experiment and validation experiment. In the first experiment, ten of newly laid C. cephalonica eggs were placed with a povinal glue and arranged in two rows $(0.5 \mathrm{~cm} \times 0.4 \mathrm{~cm}$ distance $)$ on a piece of exposure arena (a Padalarang paper) of $2 \mathrm{~cm} \times 1 \mathrm{~cm}$ size. Five of such systems (containing a total of 50 C. cephalonica eggs) were each exposed to a gravid female $T$. chilonis of the $6^{\text {th }}$ generation for 24 hours under 100 watts of illumination in an oviposition test tube. Following the withdrawal from the oviposition tube the eggs were each observed daily for their color and size and the sex of the emerged $T$. chilonis progeny was documented. The colors were scored using a grayscale from 1 to 7 , where $1=$ creamy white, $2=$ gray, $3=$ gray with black dots, $4=$ gray with black spots, $5=$ blackish gray, $6=$ grayish black, and $7=$ black (Figure 1 ). The egg size was measured using Olympus micrometers (a $10 \mathrm{x}$ eyepiece Model NCWHK and 1/100 objective Model OB-M). The longest axis in the cross-section of a $C$. cephalonica egg was taken to be the size of the egg (in $\mu \mathrm{m}$ ). The sex of emerging $T$. chilonis progeny was determined using antennal segmentation and ornamentation as the delimiting character (Pinto \& Stouthamer, 1994). Individuals whose antennae each consisting of a single, elongate flagellar segment fringed with long and robust hairs were taken to be males while those whose antennae each consisting of three flagellar segments (two funicular + one claval) ornamented with delicate, short, and less hairs to be females. The frequencies of either sex were plotted against the color score and size of C. cephalonica egg from where they emerged. The results of characterization experiment (prediction) were then tested in the validation experiment.

The validation experiment was set by exposing similar C. cephalonica eggs to gravid T. chilonis females in the oviposition tube as above. However, in this experiment the total number of the exposed eggs was 250 which were placed randomly in groups of 50 on exposure arenas of $7 \mathrm{~cm} \mathrm{x} 1 \mathrm{~cm}$ each. As were in the first experiment, the eggs color and size in this experiment were observed daily after exposure to gravid female T. chilonis for 24 hours and under 100 watts illumination. But the egg color score and size data in this experiment were used to predict the proportion of any sex of $T$. chilonis progeny prior to their emergence. The proportion of female $T$. chilonis progeny was predicted as $p_{1}$ and that of male as $q_{1}$ where $q_{1}=1-p_{1}$. The proportion of females is the ratio between the number of female individuals and the total number individuals (i.e. $\mathrm{n}_{1}=$ females + females). Meanwhile, it was predicted that females of $T$. chilonis progeny emerged from parasitized $C$. cephalonica eggs color-scored $2-5$ or sized $\geq 500$ $\mu \mathrm{m}$ and that males of $T$. chilonis progeny emerged from those eggs color-scored $6-7$ or sized $<500$ $\mu \mathrm{m}$. Thus,

$$
p_{1}=\frac{\mathrm{X}_{1}}{\mathrm{X}_{1}+\mathrm{Y}_{1}}
$$

where $\mathrm{X}_{1}=$ number of parasitized $C$. cephalonica eggs color-scored $2-5$ or sized $\geq 500 \mu \mathrm{m}$ and $\mathrm{Y}_{1}=$ number of parasitized $C$. cephalonica eggs colorscored $6-7$ or sized $<500 \mu \mathrm{m}$. Then, following their emergence, each $T$. chilonis progeny of either sex was tallied as such that the real (observed) proportion of females $\left(p_{2}\right)$ were documented as follow:

$$
p_{2}=\frac{X_{2}}{X_{2}+Y_{2}}
$$

where $\mathrm{X}_{2}=$ actual number of $T$. chilonis females and $\mathrm{Y}_{2}=$ actual number of $T$. chilonis males emerged from parasitized C. cephalonica eggs.

Analysis was done in two steps. First, a twotailed Z-test with critical regions of $<-1.96$ and $>$ 1.96 was used to test whether the prediction about $p$ held, i.e. whether the observed proportion of $T$. chilonis females $\left(p_{2}\right)$ was true as predicted $\left(p_{1}\right)$. The $p_{1}$ $-p_{2}$ difference was tested at 0.05 level of significance using the following Z-statistic (Walpole, 1982):

$$
\text { Z-statistic }=\frac{p_{1}-p_{2}}{\sqrt{ }\left(p_{1} q_{1} / \mathrm{n}_{1}\right)+\left(p_{2} q_{2} / \mathrm{n}_{2}\right)}
$$

where $\mathrm{n}_{1}=\mathrm{n}_{2}=\mathrm{n}$ (number of parasitized T. chilonis eggs) $=X_{1}+Y_{1}=X_{2}+Y_{2}$. Second, a one-tailed Z-test with a critical region of $>1.645$ was used to see whether the values of $p_{2}$ were greater than 0.5 , i.e. whether population of (parasitized) C. cephalonica 

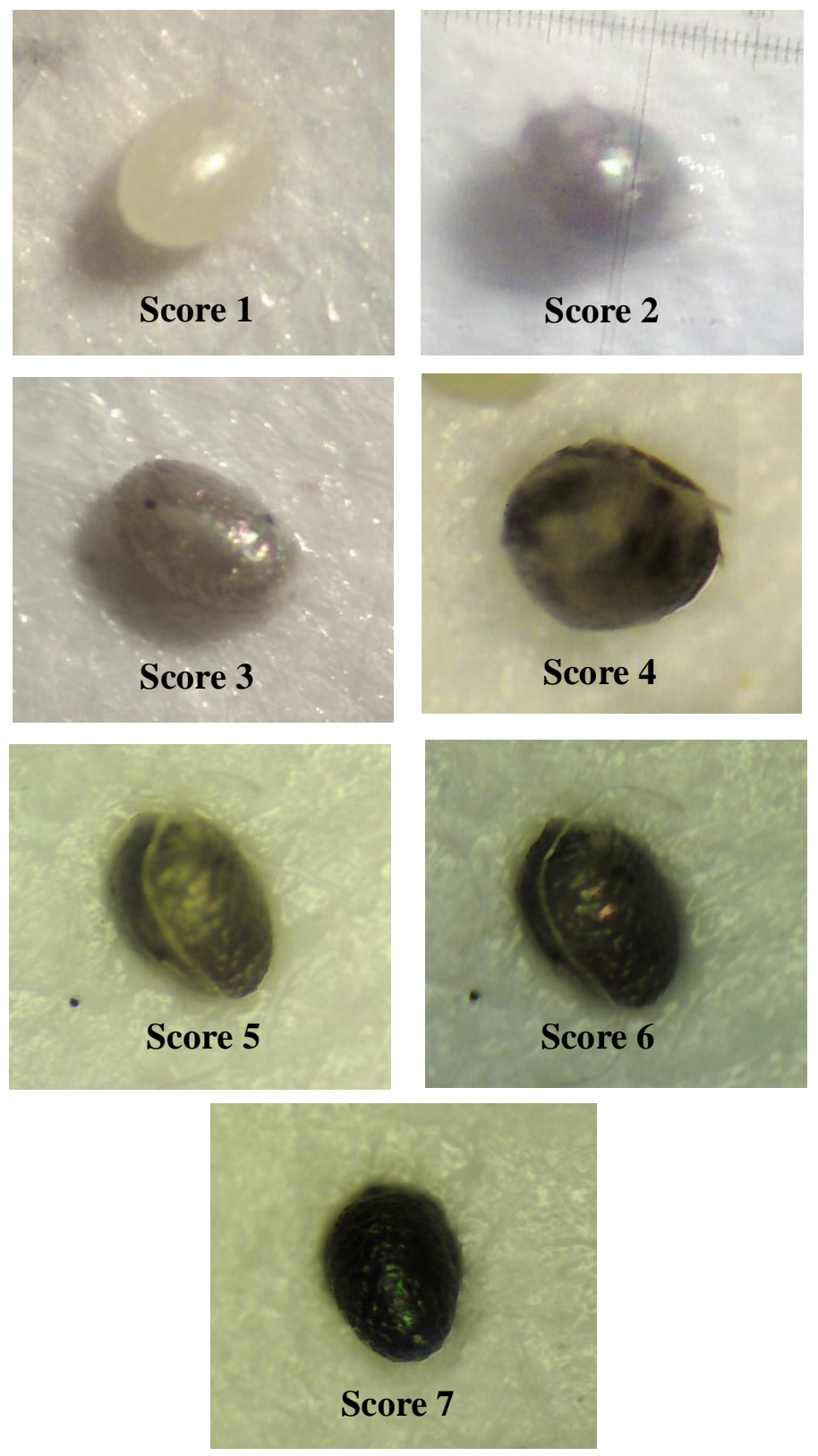

Figure 1. The colors of Corcyra cephalonica eggs scored in a gray scale from 1 to 7 
eggs consisting of larger proportion of those colorscored $2-5$ (light) or sized $\geq 500 \mu \mathrm{m}$ (large) would indeed facilitate the emergence of more $T$. chilonis females than males (with sex ratio $>0.5$ ). The test was done at 0.05 level of significance using the following Z-statistic (Walpole, 1982):

$$
\text { Z-statistic }=\frac{p_{2}-0.5}{\sqrt{ } p_{2} q_{2} / \mathrm{n}}
$$

where $p_{2}, q_{2}$, and $\mathrm{n}$ are as above.

\section{RESULTS AND DISCUSSION}

Result from characterization experiment showed that either sex of $T$. chilonis progeny emerged from parasitized C. cephalonica eggs of any color score or size. The actual parasitization was high $(92 \%)$. The parasitized $C$. cephalonica eggs facilitated the emergence of more females of $T$. chilonis progeny $(56 \%)$ than males (44\%), giving a female-biased sex ratio. Within the female population, a bigger proportion (88\%) emerged from the light colored, 2 5 scored eggs. In contrast, most males of $T$. chilonis (75\%) emerged from the darker scored C. cephalonica eggs $(6-7)$ (Figure 2). In term of size, smaller $C$. cephalonica eggs $(<500 \mu \mathrm{m})$ facilitated the emergence of more males (79\%) than females of $T$. chilonis whereas more females (76\%) emerged from relatively larger host eggs $(\geq 500 \mu \mathrm{m})$ (Figure 3). There was no absolute cut-offs for either sex manifestation of $T$. chilonis in terms of $C$. cephalonica egg color score or size. It was even true that both sexes of $T$. chilonis progeny also emerged from a small portion (4\%) of parasitized C. cephalonica eggs (color score $2-4$ and size $550-575 \mu \mathrm{m}$ ). However, there were two apparent cut-off indicators for emergence of $T$. chilonis sex, i.e. C. cephalonica egg color score of 5 (blackish gray) and egg size of 500 $\mu \mathrm{m}$. The test results showed that light-colored (scored $\leq 5$, from gray to blackish gray) or larger (sized $\geq 500$ $\mu \mathrm{m}) C$. cephalonica eggs facilitated the emergence of more $T$. chilonis females. It was thus predicted that larger proportion of females in the T. chilonis progeny population (female-biased sex ratio) should be resulted from the population of parasitized $C$. cephalonica eggs with higher proportion of those color-scored $1-5$ (first prediction) or sized $\geq 500 \mu \mathrm{m}$ (second prediction).

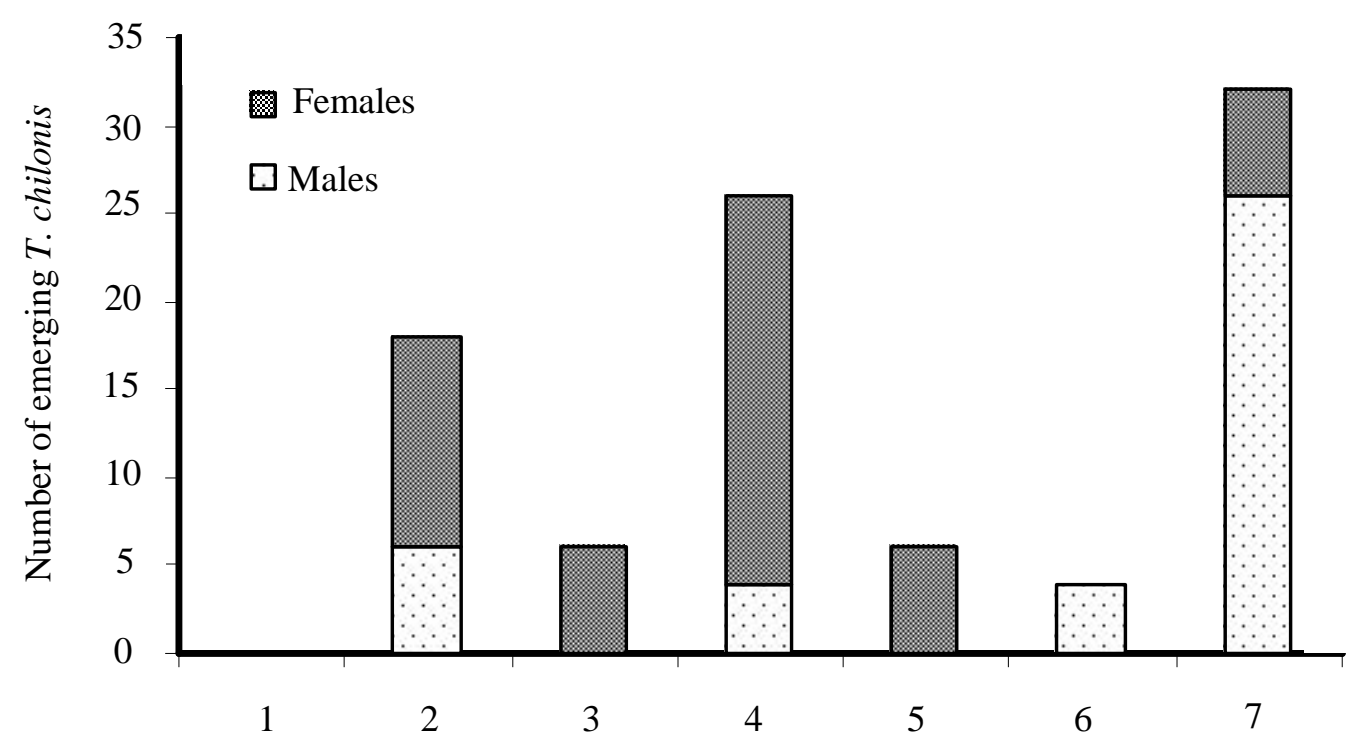

Color score of C. cephalonica eggs

Figure 2. Number of emerging T. chilonis of either sex from the parasitized C. cephalonica eggs of various color scores 


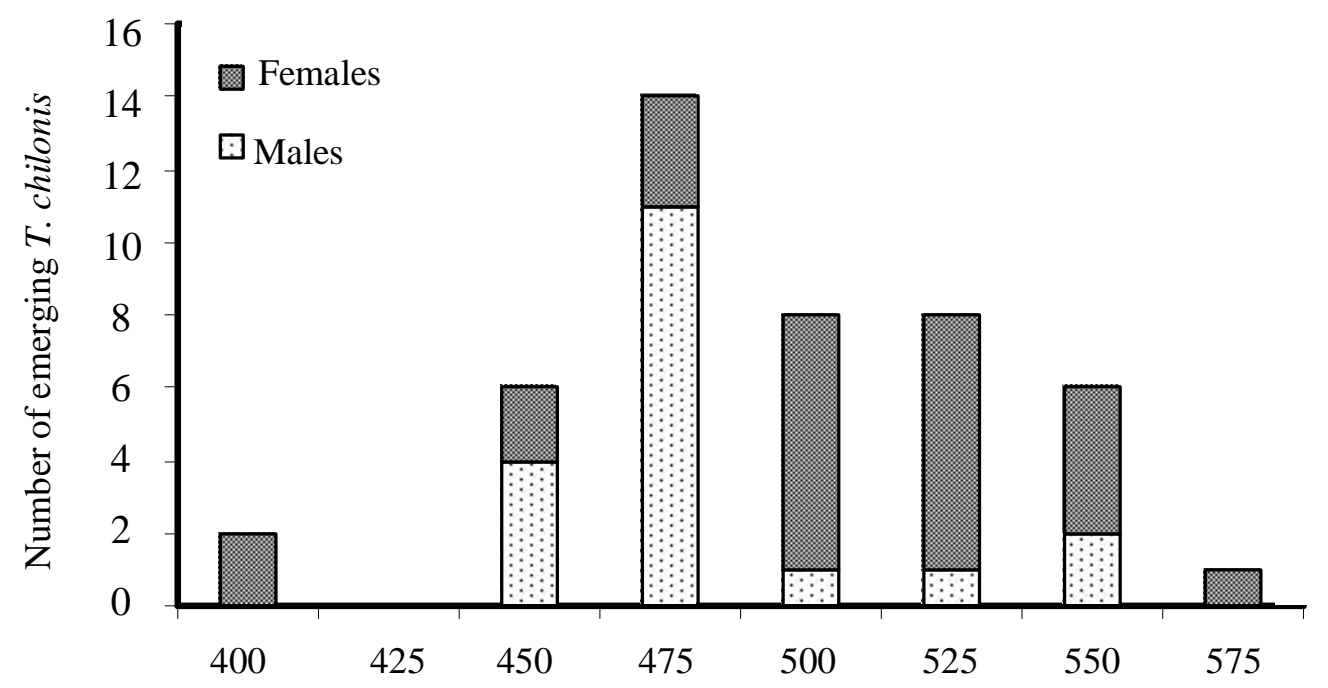

Size of C. cephalonica eggs $(\mu \mathrm{m})$

Figure 3. Number of emerging T. chilonis of either sex from the parasitized C. cephalonica eggs of various sizes

The results of validation experiment showed that the first and second prediction of the characterization experiment held (Figure 4 and Figure 5). As depicted in both figures, the observed female proportions $\left(p_{2}\right)$ in general were true as predicted $\left(p_{1}\right)$. Figure 4 showed that batches consisting of more parasitized $C$. cephalonica eggs scored $2-5\left(0.60 \leq p_{1} \leq 0.94\right)$ indeed produced more females $\left(0.70 \leq p_{2} \leq 0.78\right)$ than males of $T$. chilonis. Figure 5 also showed that more females $\left(0.64 \leq p_{2} \leq 0.83\right)$ than males of $T$. chilonis were produced from those batches consisting of $C$. cephalonica eggs sized $500 \mu \mathrm{m}$ or larger $\left(0.58 \leq p_{1} \leq\right.$ $0.79)$. All observed proportions of the female cases $\left(p_{2}\right)$ were not different from those hypothesized $\left(p_{1}\right)$ at 0.05 level of significance, except in two cases which were predicted using $C$. cephalonica egg color at 4 days prior to emergence (Figure 4). All observed female proportion cases predicted using egg color were significantly greater than 0.5 (female-biased sex ratio) (Table1) and all cases predicted using egg size were also significantly greater than 0.5 (Table 2). As an implication from the prediction on the sex proportion, the results shows that higher number of $T$. chilonis females than males indeed emerged from lighter-colored (Figure 6) or larger-sized $C$. cephalonica egg populations (Figure 7).

The color or size of $C$. cephalonica eggs could relate to the body color or size of $T$. chilonis. It was no surprise when darker parasitized host eggs produced more males while the lighter ones produced more female parasitoids because $T$. chilonis male body color is indeed darker than that of female. In other words, the parasitoid body color is manifested in the parasitized host egg color. Similar principle could work for the size: larger host eggs produces larger (i.e. female) parasitoids. In this study the predictions about proportion of female parasitoid using host egg color and size were met. In other words, color and size of the host eggs are good indicators for the parasitoid sex ratio. But other factor may affect the female-biased sex ratio of $T$. chilonis in this study and other (for instance in Putri, 2006). It has been well established that most, if not all, members of Hymenoptera (ants, bees, wasps) are arrhenotokous, i.e. their unfertilized eggs develop into males while fertilized eggs develop into females, and T. chilonis as a wasp does that. A successful egg fertilization would produce females, while a failure would end up with males. One of the adaptive strategies to couple with this reproductive 


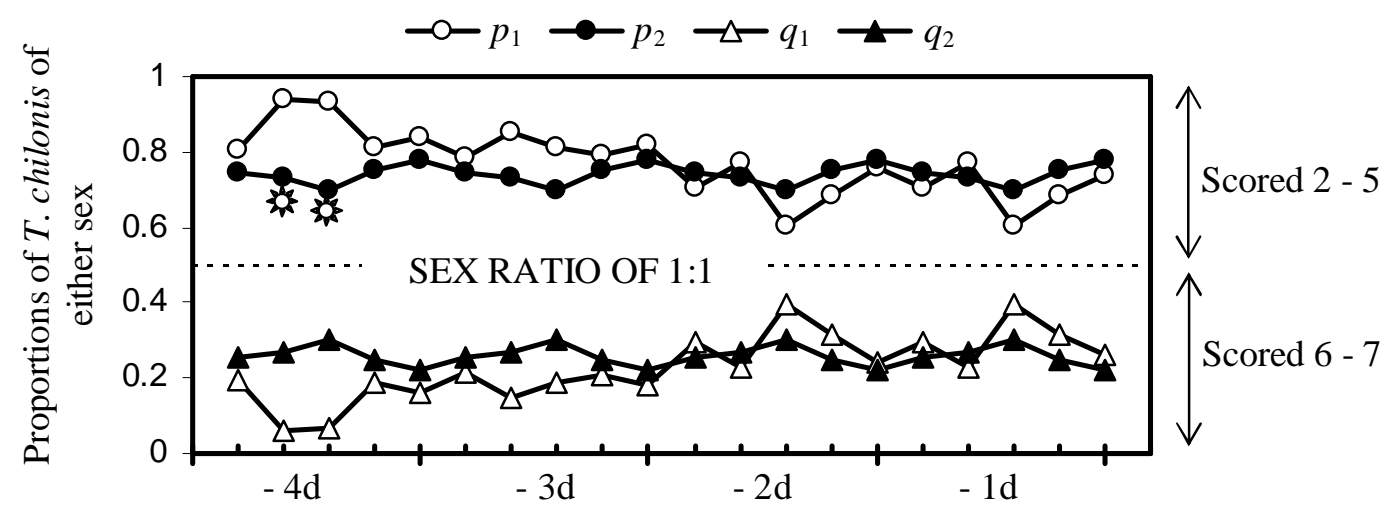

Days prior to emergence from C. cephalonica eggs

Figure 4. Predicted and observed proportions of T. chilonis of either sex that emerged from more $C$. cephalonica eggs scored light $(2-5)$ than dark $(6-7)\left(p_{1}=\right.$ predicted female proportion, $q_{1}=$ predicted male proportion, $p_{2}=$ observed female proportion, $q_{2}=$ observed male proportion, sun signs $=p_{1}$ significantly different from $p_{2}$ at 0.05 level)

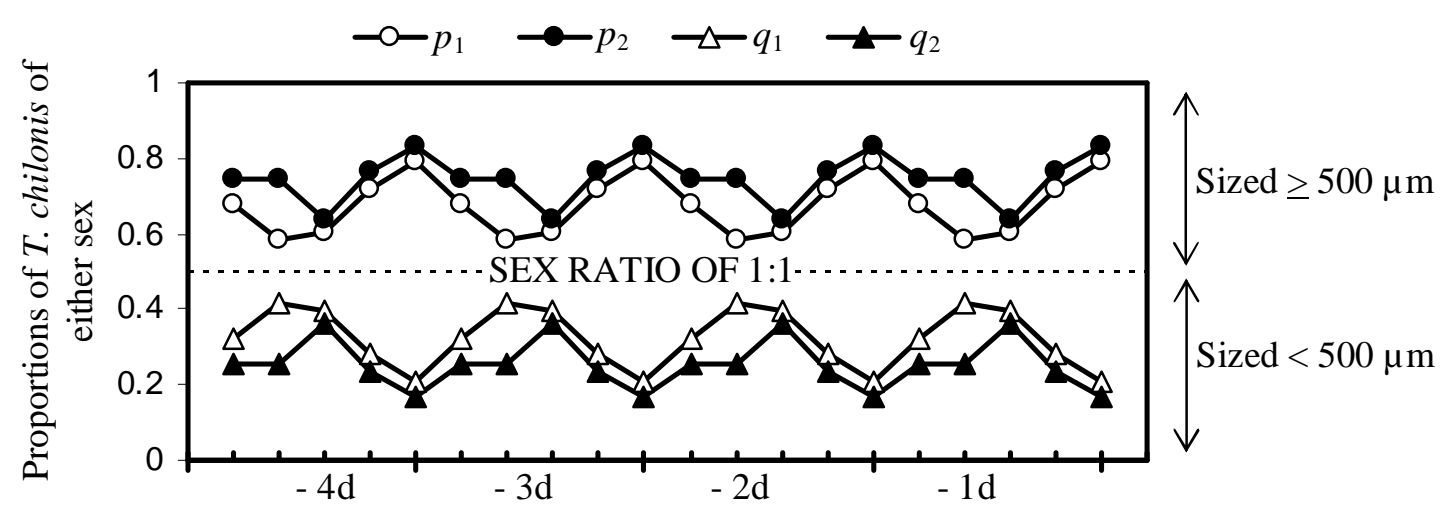

Days prior to emergence from C. cephalonica eggs

Figure 5. Predicted and observed proportions of $T$. chilonis of either sex that emerged from more $C$. cephalonica eggs sized large $(\geq 500 \mu \mathrm{m})$ than small $(<500 \mu \mathrm{m})\left(p_{1}=\right.$ predicted female proportion, $q_{1}=$ predicted male proportion, $p_{2}=$ observed female proportion, $q_{2}=$ observed male proportion, all $p_{1}$ are not significantly different from $p_{2}$ at 0.05 level) 


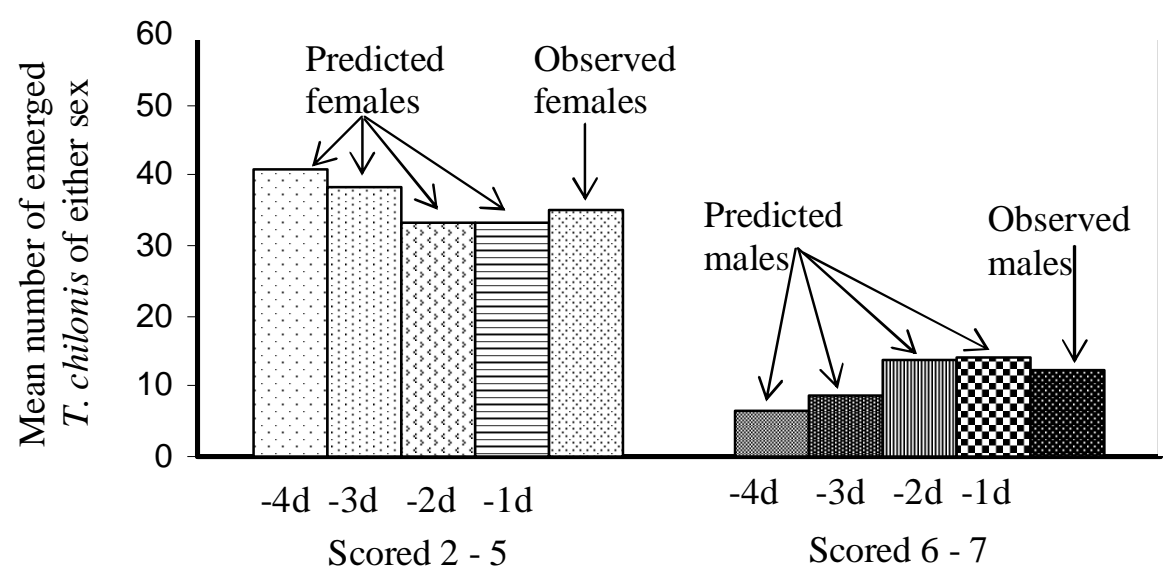

Colors of C. cephalonica eggs observed daily

Figure 6. Predicted and observed number of T. chilonis females and males emerged from lighter and darkercolored C. cephalonica eggs

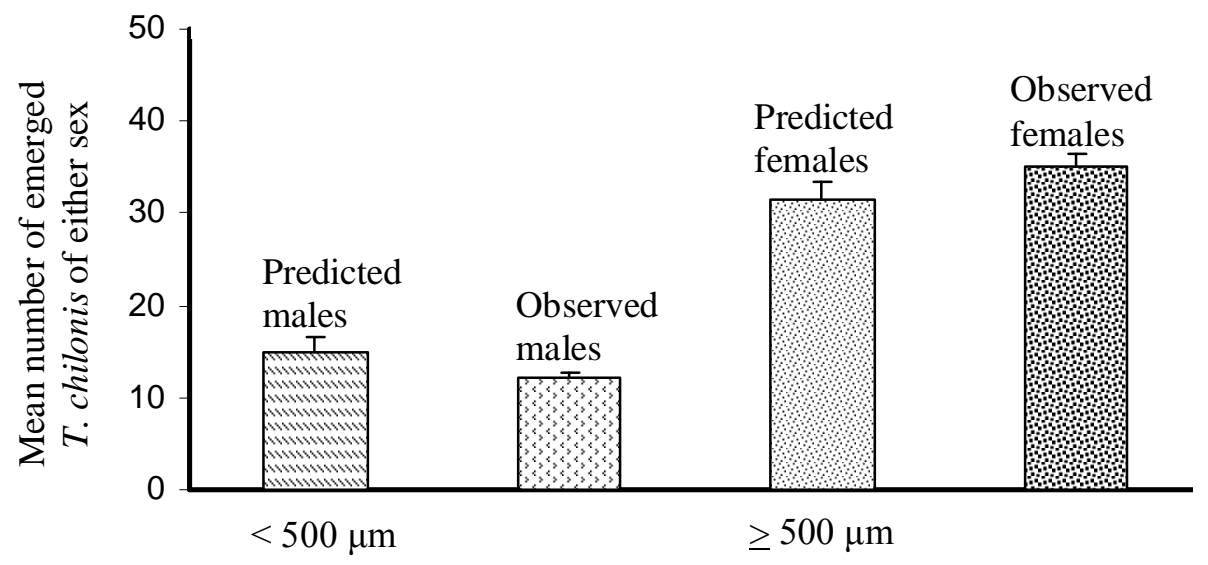

Sizes of C. cephalonica eggs

Figure 7. Predicted and observed number of T. chilonis females and males emerged from smaller and larger C. cephalonica eggs 
system is the inbreeding behavior, where brothers mate with sisters (Thornhill \& Alcock, 1983). To be effective, this behavior necessitates a brother to brother competition for access of mating with sisters (Hamilton, 1967; Alexander \& Sherman, 1977). The pressure of the competition in turn facilitates the development of a polygynous-monandrous trait where one male can fertilize many females while one female is receptive to only one male. In such a situation the female parent should produce more female than male progeny because producing additional males would not only be unnecessary but also be of wasted parental investment, as may be the case in this study.

The outcome of this study is that $T$. chilonis sex could be early-detected using the egg color or size of their factitious host, $C$. cephalonica. Detection using the color of parasitized host eggs could be done as early as four days before the parasitoid emergence. This could provide additional information about how effective (or ineffective) are the batches of parasitized host eggs before being applied to the field. A batch dominated by darker-colored host eggs would be inferior in terms of efficacy because they would produce a parasitoid population with a male-biased parasitoid sex ratio, consisting of more false parasitoids, i.e. males of $T$. chilonis that could not parasitize. For field inundation purposes, it would be beneficial to select the parasitized batches dominated by lighter-colored $C$. cephalonica eggs because those would produce $T$. chilonis population with femalebiased sex ratio consisting of more females (true parasitoids).

The host egg size, could give more profound contribution. This study shows that the host egg size could be used as the predictor for the parasitoid sex even before the egg being parasitized. This could lead to a very important technological implication for the mass-production of more effective T. chilonis in the laboratory. Methods or equipment could be developed to screen and select $C$. cephalonica eggs as such that only their larger eggs $(\geq 500 \mu \mathrm{m})$ to be prepared to produce larger number of true parasitoids ( $T$. chilonis females) being ready for the field release.

\section{CONCLUSIONS}

The first part of this study predicted that $T$. chilonis male progeny tended to emerge from $C$. cephalonica eggs that turned darker following oviposition by parent parasitoid while larger $C$. cephalonica eggs tended to facilitate emergence of $T$. chilonis females. The second part of this study showed in general that the predictions held. Batches of $C$. cephalonica eggs turning not as dark (gray scale of $2-5$ ) following parasitization produced more females (proportion > 0.5) than males of $T$. chilonis. Parasitization on larger-sized host eggs $(\geq 500 \mu \mathrm{m})$ also produced more T. chilonis females. The latter opened opportunities to enhancement of the parasitoid mass-rearing technology in the laboratory.

\section{ACKNOWLEDGEMENTS}

Appreciation goes to all staff at Biocontrol Research \& Development Laboratory, PT Gunung Madu Plantations, Terusan Nunyai - Central Lampung, for assistance during the course of this study. Upit Anggara Putri, Ita Afria Ratna Tungga Dewi, and Desi Ekawati deserve special gratitude for the fruitful team working in the laboratory. We also thank two independent reviewers for invaluable comments and suggestions.

\section{LITERATURES CITED}

Alexander, R.D. \& P.W. Sherman. 1977. Local mate competition and parental investment in social insects. Science 196: 494 - 500.

Dewi, I.A. R.T. 2007. Daya parasitasi Trichogramma chilonis Ishii terhadap penggerek batang di pertanaman tebu bergantung pada waktu aplikasi parasitoid. Skripsi. Universitas Lampung. $28 \mathrm{hlm}$.

Hamilton, W. D. 1967. Extraordinary sex ratios. Science 146: 477 - 488.

Li, Y.L. 1994. Worldwide use of Trichogramma for biological control on different crops: a survey. Pages 37 - 53 in: Wajnberg, E. \& S.A. Hassan, eds. Biological Control with Egg Parasitoids. CAB International, Wallingford, UK.

Pinto, J.D. \& R. Stouthamer. 1994. Systematics of the Trichogrammatidae with emphasis on Trichogramma. Pages $3-36$ in: Wajnberg, E. \& S.A. Hassan, eds. Biological Control with Egg Parasitoids. CAB International, Wallingford, UK. 
Putri, U.A. 2006. Daya parasitasi Trichogramma chilonis Ishii (Hymenoptera: Trichogrammatidae) di laboratorium ditentukan oleh kepadatan populasi parasitoid dan inangnya. Skripsi. Universitas Lampung. $58 \mathrm{hlm}$.

Sunaryo. 1988. Pedoman pembiakan parasitoid di PT Gunung Madu Plantations. PT GMP, Terusan Nunyai - Lampung Tengah.
Thornhill, R. \& J. Alcock. 1983. The Evolution of Insect Mating Systems. Harvard University Press, Cambridge, etc.

Walpole, R.E. 1982. Introduction to Statistics. $3^{\text {rd }}$ ed. Macmillan Publ., New York. 